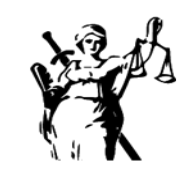

JUSTICIA

ISSN impreso 0124-7441
ISSN digital 2590-4566

\title{
Política criminal contra el hurto en Colombia 2016-2020
}

\section{Criminal policy against theft in Colombia 2016-2020}

\author{
(iD) \\ Adelaida María Ibarra Padilla \\ Universidad Militar Nueva Granada, Colombia \\ adelaida.ibarra@unimilitar.edu.co
}

\author{
(iD) \\ Gloria Cristina Martínez Martínez \\ Universidad Militar Nueva Granada, Colombia \\ abogadacristinam@gmail.com
}

\author{
(iD) \\ Esquid Bernardo Mena Bermúdez \\ Universidad Militar Nueva Granada, Colombia \\ ebmena@coruniamericana.edu.co \\ Recibido: 14 de mayo de 2020 / Aceptado: 26 de julio de 2020 \\ https://doi.org/10.17081/just.26.39.4312

\section{Resumen}

El hurto figura entre los comportamientos delictivos que más afectan los bienes particulares y que mayor incidencia tiene en la precepción de inseguridad ciudadana. La política criminal estatal ha resultado ineficaz en su labor de reducir este delito y garantizar la protección de los bienes de sus habitantes, conforme al mandato constitucional y, por el contrario, se observa una tendencia al alza. Esta situación revela la necesidad de establecer las diferentes causas que lo generan y las políticas públicas que se vienen implementando para la garantía del patrimonio económico. Para ello, este estudio analiza desde una perspectiva criminológica el abordaje del tema en el país y su conformidad con las garantías y derechos fundamentales de los infractores. Se concluye que la política criminal en esta materia ha sido principalmente represiva, aunque en los últimos años se observa un incremento en las medidas jurídicas y sociales de carácter preventivo e integral.

PALABRAS ClAVe: política criminal, hurto, política preventiva, política integral, mecanismos alternativos de solución de conflictoss.

\begin{abstract}
The crime of theft is among the criminal behaviors that most affect private assets and that has the greatest impact on the perception of citizen insecurity. The state criminal policy has been ineffective in its work to reduce this crime and guarantee the protection of the property of its inhabitants, in accordance with the constitutional mandate and, on the contrary, there is an upward trend. This situation reveals the need to establish the different causes that generate it and the public policies that are being implemented to guarantee the economic heritage, a legal asset affected by this criminal behavior. For this, this study analyzes from a criminological perspective the approach given to the subject in the country and its conformity with the fundamental rights and guarantees of the offenders. It is concluded that criminal theft policy has been mainly repressive, although in recent years there has been an increase in preventive and comprehensive legal and social measures.
\end{abstract}

KEYWORDS: academic honesty, improvement, legal principles, academic environment, modern science, reputation of scholars.

Como Citar: Ibarra Padilla , A. M., Martínez Martínez , G. C., \& Mena Bermúdez , E. B. (2021). Política criminal contra el hurto en Colombia 2016-2020. Justicia, 26(39), 237-254. https://doi.org/10.17081/just.26.39.4312 


\section{Introducción}

Entre los principales fines del Estado colombiano como Estado Social de Derecho están "garantizar la efectividad de los principios, derechos y deberes consagrados en la Constitución" y "asegurar la convivencia pacífica" (Constitución, 1991, art. 1). Esta última se ve alterada por el fenómeno antisocial del hurto.

El hurto a personas es uno de los comportamientos con mayor impacto en la percepción de seguridad. Según informe de la Fiscalía General 2018-2019, a nivel nacional, el mayor número de denuncias presentadas a través de la plataforma ¡ADenunciar! corresponde al hurto a personas. En la capital del país este delito corresponde al $81 \%$ de las denuncias, en Medellín al 68\%, en Florencia, Neiva, Bucaramanga y Soacha están entre el 65\% y 75\%; mientras que en Cali, Cartagena, Barranquilla, Santa Marta, Villavicencio, Pereira, Cúcuta y Manizales entre el $60 \%$ y el $65 \%$ (Fiscalía, 2019). Estos datos ponen de relieve la necesidad de analizar las medidas que se vienen implementado para enfrentar esta problemática, más aún cuando el hurto viene acompañado de lesiones personales u homicidio.

Las estrategias adoptadas por los Estados para combatir la delincuencia son diversas y van desde su ataque frontal, el fortalecimiento de los organismos de inteligencia y el ataque a las estructuras financieras del crimen organizado, hasta el atender sus orígenes dentro del tejido social. Así, la política criminal tiene dos tipos principales de población objetivo: por un lado, los delincuentes condenados y por el otro, las personas que, por su entorno social, son susceptibles de realizar actividades fuera de la ley (García, 2018).

Este trabajo tiene por objeto analizar las estrategias que están siendo implementadas contra el hurto, sus fortalezas y falencias. Esta investigación es de tipo socio-jurídica con alcance descriptivo, en la cual se estudian en detalle las principales características, facetas y factores de riesgo del fenómeno del hurto a personas. Se basa en un análisis documental, normativo y doctrinal sobre dicho tipo penal. La técnica utilizada es la revisión documental que incluye literatura especializada como revistas científicas, normas jurídicas del orden constitucional y legal, jurisprudencia de las altas cortes, conceptos doctrinales, e informes oficiales de las principales autoridades públicas responsables de la temática como la Policía Nacional y el Ministerio de Defensa Nacional.

La investigación es de enfoque cualitativo y de diseño no experimental, se basa en la interpretación $y$, aunque se presentan algunos de datos estadísticos, estos son solo ilustrativos. Esta investigación no pretende probar una hipótesis. Se escogió el enfoque cualitativo por ser el más apropiado para explicar fenómenos socio-culturales y permitir la contextualización y un punto de vista holístico del fenómeno estudiado.

El documento se encuentra dividido en cuatro secciones: la primera estudia las principales posturas teóricas en cuanto a la política criminal; la segunda presenta el desarrollo normativo en el país frente a la problemática del hurto; la tercera analiza los diferentes factores que inciden en la ocurrencia de este delito y la cuarta sección reflexiona sobre las medidas que se vienen implementando en el país para combatirlo.

\section{Política criminal en Colombia: concepto, características y jurisprudencia}

Una política pública es toda intervención estatal diseñada para alcanzar unos objetivos propuestos que, mediante el desarrollo de una serie de pasos o procesos detallados y específicos, pretenden satisfacer las necesidades de una comunidad o resolver problemáticas dentro de un grupo social (Roth, 2002). 
El Ministerio de Justicia (2019) define la política criminal como "una política pública orientada hacia los fenómenos definidos por la ley penal como delitos. Sus estrategias se orientan a la prevención, control, investigación y sanción de la criminalidad, la atención a las víctimas y el tratamiento de los condenados"; por lo tanto, intervienen los tres poderes: el legislativo al expedir las leyes que criminalizan conductas, el judicial al investigar, juzgar y sancionar el comportamiento prohibido y el ejecutivo con el cuerpo de policía y el sistema penitenciario.

La política criminal ha sido definida por la Corte Constitucional como:

El conjunto de respuestas que un Estado estima necesario adoptar para hacerle frente a conductas consideradas reprochables o causantes de perjuicio social con el fin de garantizar la protección de los intereses esenciales del Estado y de los derechos de los residentes en el territorio bajo su jurisdicción. (Sentencia C-646, 2001)

El alto tribunal, siguiendo los planteamientos de Baratta (2004), referencia tres clases de criminalización: la primaria se da cuando el legislador crea los tipos penales; la secundaria cuando se adjudica la responsabilidad penal y una terciaria que se concreta en el momento en que empieza a ejecutarse la pena.

La Corte Constitucional reconoce la necesidad de una fase de prevención, con una estrategia integral contra la criminalidad que aborde los principales factores de riesgo. Para la Corte, la política criminal presenta varias dimensiones; la dimensión social promueve el deber de alertar a las autoridades sobre hechos relacionados con la comisión de delitos; la dimensión jurídica se orienta a la creación o modificación de leyes penales y contravencionales; la dimensión económica se sirve de las recompensas y otros estímulos para facilitar la aprehensión de los delincuentes, así como la implementación de desincentivos que incrementen los costos a quienes cometan delitos; la dimensión cultural busca generar conciencia sobre las implicaciones negativas de la criminalidad en la sociedad; la dimensión administrativa se ocupa de mejorar la operatividad de la ley penal, por ejemplo, con mecanismos de seguridad carcelaria; por último, la dimensión tecnológica pone adelantos científicos al servicio de la prevención, investigación y sanción del delito (Sentencia C-646, 2001).

\section{Política criminal represiva}

El Estado Social de Derecho ubica al ser humano en el centro del escenario legal y, en consecuencia, las normas deben optimizar sus derechos. La libertad se consagra como uno de las garantías constitucionales más importantes dada su propia naturaleza y las políticas represivas atacan fuertemente su núcleo esencial.

El sistema jurídico colombiano tiene fuertes raíces en la tradición liberal europea (Guerrero, 2017), en la cual, el daño y el libre albedrío constituyeron el fundamento de la responsabilidad penal. El proceso se erigió como un escenario idóneo de garantía de los derechos del reo, de manera que la imposición de la pena se supeditó a la comprobación de la culpabilidad. La pena, de naturaleza aflictiva y dolorosa, sólo se podía imponer a quien hubiese causado deliberadamente un mal, porque con esa misma capacidad de reflexión, el individuo podía sentir en carne propia la agonía y amargura de la intervención punitiva en su libertad (Carrara, 2000). Esto explica que el fin de la pena fuera retributivo (Alexy, 1989), pues con ella, el aparato represor del Estado buscaba la expiación, la purgación y purificación del reo. 
El derecho en general y el penal, en particular, no deja de ser un instrumento aflictivo y como tal se aplica. Los conceptos de expiación, sufrimiento, penitencia, gravitan en el derecho penal; esa presencia no es causal o inocente. La idea de atribuirle capacidad expiatoria al sufrimiento penal y penitencial responde a una arraigada tradición que no desapareció con la Modernidad. (Cruz, 2011, p. 690)

La legalidad procesal basada en la obligatoriedad de la acción penal, surgió a partir del entendimiento del proceso como garantía de un juicio justo de comprobación de responsabilidad (Gómez, 2007). A su vez, el fin retributivo de la pena empezó a comprenderse como ingrediente imprescindible del restablecimiento del daño a la colectividad causado con el delito. De estos análisis, surgió el concepto social de la inevitabilidad del castigo (Tamayo, 2016).

El carácter represor y expansivo del derecho penal se fortaleció después de la segunda guerra mundial, con la constitución del Tribunal de Núremberg que impuso fuertes castigos a los militares alemanes responsables de delitos execrables (Nino, 1996). El desconocimiento del principio de legalidad, la vulneración del derecho a un juez independiente e imparcial y la exigencia de la pena de muerte, plantearon un panorama diferente del castigo, como un mecanismo político forzoso para satisfacer las necesidades de justicia.

En los sistemas penales represivos, el castigo es el eje central; no obstante, la vox populi incide en su contenido y alcance, con particular afectación en el diseño de la política criminal. "El populismo en la política penal rechaza el criterio de los expertos y profesionales de la criminología y el derecho penal, imponiendo la autoridad de "la gente", del "sentido común", la "lógica de lo básico". (Cruz, 2011, pp. 691-692). El encierro intramuros prima facie es una medida simple, por los costos que representa frente al deber de resocializar. La política criminal desde una visión represiva se basa en el temor por el castigo, y que "la cárcel, que es la culminación de un proceso de violencia selectiva, es la respuesta adecuada y acertada para erradicar la violencia delictiva. Se sabe muy bien que el encierro no es necesario, en todos los casos" (Cruz, 2011, p. 689).

En el cambio del Estado liberal al Estado intervencionista en Europa, la escuela positivista del derecho penal erigió el castigo como un mecanismo de salvaguarda social. El fundamento ya no estaría afincado en la necesidad de retribuir el mal causado, sino de enviar un mensaje a la sociedad y al infractor de las consecuencias negativas del delito, para que no incurran en él o para que el mismo no se vuelva a presentar (Agudelo, 2008).

El sistema legal colombiano heredó la prevención general y especial, como fines de la pena con un fuerte contenido ejemplarizante, sin olvidar los aspectos retributivos, lo que explica que el artículo 4 del Código Penal haya contemplado la prevención general y especial, la retribución justa, la reinserción social y la protección al condenado como funciones de la pena (Guerrero, 2017).

Las políticas públicas basadas en el castigo ejemplarizante para prevenir el delito resultan insuficientes. Para poder generar un impacto significativo en la sociedad se requiere "una estrategia de prevención del delito que anticipe las condiciones propiciatorias de la acción violenta y contenga el impulso criminal" (Soto, 2010, p. 58).

El encarcelamiento solo es inevitable para un grupo minoritario de infractores: es un error naturalizarla pena, "porque siempre debe reconocerse al infractor, dependiendo de la gravedad del hecho criminal, opciones compatibles con los objetivos de la pena en un Estado social y democrático de Derecho" (Cruz, 2011, pp. 698-699). 


\section{Política criminal preventiva}

Reyes (1996, p. 366) define la prevención como:

La parte de la política criminal que tiene por objeto minimizar la ocurrencia de la criminalidad, la cual está constituida por una gran gama de actividades que van desde el alumbrado público, para evitar que el criminal aprovechándose de los sitios oscuros lleve a cabo sus actos desviados, hasta el desarrollo integral de un país atendiendo a factores como la educación, el empleo, la salud y vivienda para que los factores desencadenantes de la conducta desviada no desemboquen en actos criminales. (Reyes, 1996, p. 366)

Soto (2010, p. 51) distingue tres tipos de prevención: la punitiva, basada en la intimidación, en el desistimiento por medio de la amenaza penal; la mecánica, encaminada a crear obstáculos que le cierren el camino al delincuente; la colectiva, dirigida a detectar, tratar y eliminar los factores criminógenos en una forma no penal.

Prevenir requiere implementar una serie de mecanismos que permitan la convivencia pacífica, entre ellos, la solución de los conflictos. Las falencias de atención oportuna de la conflictividad que vive el país ha conducido alto grado de violencia y criminalidad. La prevención de la delincuencia si bien recae principalmente en el sector de seguridad pública del gobierno, esta debe estar acompañada de la participación de la ciudadanía (Soto, 2010).

\section{Política criminal integral}

La política criminal integral es definida como "un conjunto amplio, complejo y diversificado de medidas y acciones desarrolladas bajo el impulso del estado pero con amplia participación comunitaria, tendiente a reducir, limitar y atenuar el delito en general, la violencia como base y todo ello promoviendo el ascenso social de la población y el desarrollo económico social del país" (Aparicio, 2009, par. 9).

La Política Criminal Integral procurará que el delincuente no pueda delinquir (Prevención Situacional), pero fundamentalmente procurará que el niño o joven, especialmente el marginal, no se convierta en delincuente; que otros no se hagan adictos a las drogas; que se reduzca la circulación ilegítima de armas de fuego, que se refuercen los sistemas educativos y recreativos para la niñez y la juventud; que se brinde apoyo a la familia de bajos recursos; que se organicen los barrios y las comunidades participativamente y que en cada zona se creen esquicios de prevención en coordinación con la policía; que se involucren todos en recuperar el espacio urbano muchas veces "desertizado" por haber sido abandonado por los vecinos y copado por los delincuentes. (Aparicio, 2009, par. 12)

La política criminal debe ser objeto de seguimiento y control; por ejemplo, se debe evaluar y reacondicionar las cárceles, así como examinar la actividad judicial en relación con los postulados del derecho penal como última ratio, con carácter fragmentario y protector de bienes jurídicos, para evitar las medidas de endurecimiento punitivo (Sentencia T-388, 2013).

Las instituciones jurídico penales deben ir más allá de la mera eficiencia numérica del sistema y atender a los principios y garantías que sustentan el modelo jurídico, político y económico del país, "evitando la excesiva criminalización del ciudadano y de caer en la trampa, siempre armada, del populismo penal" (Juárez \& Medina, 2011, p. 165). 
Una política integral involucra a todo el aparato estatal; se enfoca en los derechos humanos; no se limita a un mandato de gobierno; asegura altos niveles de consenso social y político y evita la incidencia de intereses político-electorales erigidos únicamente en favor de la seguridad interna. En este escenario la gestión local, la participación democrática, el fortalecimiento de la gobernabilidad regional y municipal, las reformas integrales del sistema judicial y la cooperación internacional son esenciales para consolidar políticas criminales integrales. (Faroppa, 2005)

El éxito de una política pública integral ubica los derechos humanos como eje central y la participación de la ciudadanía como factor fundamental en su implementación y evaluación.

\section{Marco jurídico de la política criminal en Colombia}

\section{Bases constitucionales de la política criminal colombiana}

El derecho penal sustancial y procesal está constitucionalizado. El primero debe estar adecuadamente configurado hacia el respeto por la dignidad humana del sujeto pasivo de la acción penal, de manera que pueda realizarse en el segundo. Por ello, más allá del simple pragmatismo de hacer eficiente el sistema, se examina si el derecho penal material guarda coherencia con el proceso (Jescheck, 1993).

La política criminal en Colombia se fundamenta en principios de orden constitucional (Aponte, 2010): la culpabilidad, el Estado de Derecho, el de humanidad, el de lesividad y el de exclusiva protección de bienes jurídicos, son cruciales a la hora de diseñar estrategias de lucha contra la criminalidad (Carnevali, 2008).

La Corte Constitucional ha establecido unos estándares mínimos que debe tener una política criminal; siendo un aspecto crucial la necesidad de abandonar los criterios de mera represión y del castigo por el castigo mismo y transitar hacia una perspectiva amplia de derechos que proteja a las víctimas y a los responsables. Se debe implementar una política preventiva del delito donde la acción penal sea la última opción; reforzar el respeto por el derecho a la libertad personal; propender por la efectiva resocialización de los condenados, lo cual requiere la reestructuración de los modelos de estudio y trabajo en los establecimientos penitenciarios; contemplar como excepcional toda medida que conlleve la restricción de la libertad de locomoción; debe ser coherente con los principios del Estado Social de Derecho y los derechos humanos; y sostenible desde el punto de vista financiero (Sentencia T-762 de 2015).

\section{Bases legales de la política criminal colombiana}

La Ley 599 de 2000 "Por la cual se expide el Código Penal" contempla como norma rectora el respeto por la dignidad humana, la necesidad, proporcionalidad y razonabilidad, como criterios rectores de las sanciones penales y la tipicidad, antijuridicidad y culpabilidad, como categorías necesarias e indispensables de la responsabilidad penal.

El hurto, contemplado en dicha normativa, consiste en apoderarse de un bien mueble ajeno, con la finalidad de obtener provecho para sí mismo o para un tercero. La sanción prevista en la ley para esta conducta va de 16 a 36 meses de prisión cuando la cuantía no excede los 10 salarios mínimos, o de 32 a 108 meses de prisión cuando la cuantía sea mayor a estos valores. El artículo 239, recoge el tipo penal básico, de resultado objetivo, de lesión, de conducta instantánea y mono-ofensivo. Este tipo penal solo admite la modalidad dolosa y puede ser agravado, calificado o atenuado por las circunstancias establecidas taxativamente (Ley 599,2000 , artículos 239,241 y 242). 
Asimismo, la Ley 65 de 1993 "Por la cual se expide el Código Penitenciario y Carcelario", establece como norma rectora el respeto a la dignidad humana y a los derechos humanos y prescribe que "las restricciones impuestas a las personas privadas de la libertad estarán limitadas a un estricto criterio de necesidad y deben ser proporcionales a los objetivos legítimos para los que se han impuesto" (Ley 65, 1993, art. 5).

La Ley 906 de 2004 "Por la cual se expide el Código de Procedimiento Penal" consagra la dignidad humana, la prelación de los tratados internacionales sobre derechos humanos, la imparcialidad y la legalidad, como criterios que direccionan la investigación y juzgamiento de ilícitos. Estas normas rectoras vinculan al sistema represor estatal, de manera que, su desconocimiento por parte del ente de persecución penal o del juez, conllevan a una inobservancia inaceptable de la norma constitucional (Velásquez, 2007).

El Código Nacional de Policía y Convivencia (CNPC) del 2016, establece en su artículo 95 los “Comportamientos que afectan la seguridad de las personas y sus bienes relacionados con equipos terminales móviles", entre los cuales abarca la compra, alquiler, venta, uso, distribución, almacenamiento, transporte u ofrecimiento al público de equipos terminales móviles reporte de hurto y/o extravío o cuyo número de identificación físico o electrónico haya sido reprogramado, remarcado, modificado o suprimido (Ley, 2016, 1801, art. 95)

La Ley 1577 de 2012 "Por medio de la cual se establecen estímulos tributarios y otros, con el fin de adoptar medidas especiales para la rehabilitación e inclusión social de jóvenes con alto grado de emergencia social, pandillismo y violencia juvenil" busca prevenir el hurto a partir del abordaje de sus factores de riesgo; en tal sentido, promueve la creación de planes, programas y estímulos especiales encaminados a atender las necesidades de esta población por medio de los Consejos de Política Social.

Para ello, la ley prevé la articulación de los gobiernos locales con el Instituto Colombiano de Bienestar Familiar (ICBF) para la asistencia técnica, el Servicio Nacional de Aprendizaje (SENA) para los programas de formación para el trabajo y generación de empleo como herramienta de inclusión social, el Ministerio de Educación, Icetex y universidades públicas y privadas para el impulso de estímulos educativos, el Ministerio de Protección Social para la inclusión al Sistema General de Seguridad Social y el Departamento Administrativo Nacional de la Economía Solidaria (Dansocial) para el fomento de organizaciones de economía solidaria.

\section{Mecanismos de terminación anticipada del proceso penal como herramienta de política criminal frente al hurto}

La Ley 906 de 2004 implementó diferentes instrumentos para la terminación anticipada del conflicto y la reparación de las víctimas, basados en fundamentos de justicia premial y restaurativa. El principio de oportunidad, el allanamiento a cargos, los preacuerdos y negociaciones, son ejemplos de la primera; la conciliación y la mediación, de la segunda.

Los preacuerdos y negociaciones integran un componente importante de la denominada "justicia consensuada", que es desarrollo de una política criminal, que al igual que la conciliación y los allanamientos, se encaminan a dar solución que derivan de la comisión de conductas punibles a partir del consenso o acuerdo entre el titular de la acción penal o entre los particulares involucrados, lo cual implica cesión, concesión o renuncia de derechos, todo ello en aras de una "justicia pragmática" pero igualmente eficiente. (Botero \& Uribe, 2017, p.14) 
El hurto es de los delitos de mayor ocurrencia en el país; en su ejecución intervienen personas provenientes de los sectores más vulnerables de la sociedad dedicados, por lo general, a hurtos de poca monta, "raponazo" de celulares, bolsos, bicicletas y atracos en vehículos de servicio público; a quienes el sistema les aplica medidas de endurecimiento punitivo que incide en el aumento de la población carcelaria. Esta situación se presenta, en gran parte, por la prevalencia de una práctica judicial y cultural carcelaria, que privilegia la privación de la libertad y menosprecia la justicia premial o negocial y si lo aplica lo hacen con vulneración de las garantías de los involucrados, lo cual repercute en el hacinamiento carcelario.

La aplicación adecuada de la justicia premial, negocial y restaurativa, con el debido respeto de los derechos de los involucrados en el conflicto penal, trae importantes beneficios para la administración de justicia. La descongestión de los despachos al igual que la reducción del hacinamiento carcelario son algunos de ellos.

Con el principio de oportunidad se otorga un tratamiento no punitivo a los delitos que afectan mínimamente los bienes jurídicos. En el hurto, por ejemplo, cuando la cuantía no exceda los diez salarios mínimos legales mensuales vigentes (art. 239, inc. 2, C.P.) y no fue cometido con violencia, puede aplicarse el principio de oportunidad al tenor de lo establecido en el numeral $1^{\circ}$ del artículo 324 de la Ley 906 de 2004. La conciliación preprocesal (Ley 906, 2004, art. 522), es requisito de procedibilidad para el ejercicio de la acción penal en los delitos querellables (Ley 906, 2004, art.74), como el hurto simple. Por su parte, la mediación (Ley 906, 2004, art. 523) se aplica a los delitos investigables de oficio cuya pena mínima no exceda de cinco años; el diálogo que propician estos mecanismos evita que muchos delitos lleguen a juicio.

Finalmente, en el allanamiento a cargos y en los preacuerdos el investigado, acepta su responsabilidad. Estos mecanismos tienen como fines "humanizar la actuación procesal y la pena; obtener pronta y cumplida justicia; activar la solución de los conflictos sociales que genera el delito; propiciar la reparación integral de los perjuicios ocasionados con el injusto y lograr la participación del imputado en la definición de su caso". (Reyes, 2010, p. 10)

Ahora bien, el análisis dogmático de la tipicidad, antijuridicidad y culpabilidad como categorías necesarias de la conducta punible a la luz de los artículos 9, 10 y 11 de la Ley 599 de 2000, por parte de la Fiscalía, evita la aplicación de medidas de endurecimiento punitivo y resuelve el conflicto social, sin necesidad de ir a juicio.

En Colombia, la Fiscalía ostenta la titularidad de la acción penal, conforme al artículo 250 de la Constitución Política de 1991, modificada por el Acto Legislativo 03 del 2002, la cual es de ejercicio obligatorio. Todas las denuncias que lleguen a su conocimiento, deben ser objeto de acusación y llevadas a juicio, bajo el legado de la tradición continental europea que avizoró en éste, un escenario legítimo para desvirtuar la presunción de inocencia (Acuña \& Muñoz, 2006). Asimismo, la norma mencionada le asignó al Fiscal General de la Nación la función de participar en el diseño de la política criminal y presentar proyectos de ley al respecto.

En la tradición continental se evidenció que existían circunstancias especiales, en las cuales, de llegarse a aplicar el rigor ordinario de la pena, se causaría mayor daño a la sociedad, aun cuando se obrara conforme a la justicia; se consideró, por ejemplo, que frente a daños de ínfima significación social o cuando la reprochabilidad del hecho criminoso era mínima, la pena resultaba desproporcionada. En estos eventos, se legitimaba al Estado para prescindir del proceso e incluso de la pena (Carrara, 2000). Asimismo, se propusieron teorías sobre su no imposición cuando se advirtiera su falta de necesidad, en el ámbito de la prevención general o especial; para evitar sanciones inútiles (Roxin, 1981) "o aun más perjudiciales que la conducta" (Cote, 2007, pág. 209). 
El sistema punitivo en Colombia no ha sido ajeno a estas realidades. El Acto Legislativo 03 de $2002 \mathrm{im}-$ plicó un cambio de paradigma, porque si bien contempló la obligatoriedad en el ejercicio de la acción penal, bajo los presupuestos de justicia retributiva, abordó la posibilidad de renunciar a su ejercicio, mediante la aplicación del principio de oportunidad, de manera excepcional.

La facultad de suspender, interrumpir y renunciar a la persecución penal, fue establecida en Colombia, en el marco de la política criminal, en contextos de reforma de los países de América Latina (Benavides, 2016), con fuerte incidencia de la tradición anglosajona imbuida por el pragmatismo y por hacer el sistema penal más eficaz (Garzón \& Londoño, 2006).

En Colombia se avanzó más allá del pragmatismo y del llano análisis del costo beneficio (Aponte, 2010), sin negar las ventajas prácticas de no llevar todos los casos a juicio. Los numerales 6 y 7 del artículo 250, modificado por el acto legislativo 03 de 2002 reivindicaron los intereses de la víctima y erigieron obligaciones en cabeza de la fiscalía en relación con los mismos, a través de mecanismos de justicia restaurativa.

La Corte Constitucional ha manifestado que la Ley 906 de 2004 debe garantizar una pronta reparación a las víctimas quienes, frente a la aplicación del principio de oportunidad, en principio "podrían sentirse defraudadas" al evidenciar que el sistema penal ha dejado de aplicar con rigurosidad, la sanción "en cuya efectividad confiaba"; empero les asegura una plena reparación, indispensable y condicionante de la procedencia de la oportunidad (Sentencia C-326,2016).

El esquema procesal de la Ley 906 de 2004, al no ser propiamente acusatorio (Urbano, 2018) admite la participación de las víctimas desde la etapa de la indagación, aunque con marcadas limitaciones en el juicio oral, lo que le ha permitido a la Corte Constitucional aseverar que en este sistema el derecho a la reparación es trascendente para la definición del litigio (Sentencia C-031 de 2018).

La justicia restaurativa reconoce que la víctima del delito no es el Estado, sino el particular ofendido quien puede decidir sobre el fin de la contienda, a través de un diálogo que conduzca a una solución no punitiva basada en la expectativa legítima de ver compensado el daño. En este escenario, "el fin principal del proceso es la satisfacción de los intereses del perjudicado y no los del poder" (Garzón \& Londoño, 2006, p. 101)

El principio de oportunidad se fundamenta en la justicia restaurativa. En el hurto, el Estado renuncia al ejercicio de la acción penal, si el investigado repara integralmente a las víctimas o cuando el objeto material se encuentra el alto estado de deterioro, según las prescripciones de los numerales 1 y 10 del artículo 2 de la Ley 1312 del 2009.

A pesar de los avances del ordenamiento jurídico en relación con el reconocimiento de las víctimas en el proceso penal que ha ampliado un espacio hacia el diálogo y la solución consensuada de los conflictos, la fiscalía, la defensa y los jueces han acudido a este mecanismo, por mero pragmatismo. Lo hacen para resolver la confrontación pronto, con el ánimo de ahorrarse los costos y beneficios que depara un juicio y con el propósito de descongestionar la administración de justicia.

El artículo 1 de la Ley 1312 del 2009 establece un requisito sustancial de procedencia del principio de oportunidad, que lo ata a la existencia de "fundamentos para adelantar la persecución penal", lo que en palabras de Duce (2007) y Gimeno (2001) se traduce en la exigencia para el Estado de contar con un mínimo probatorio del cual se pueda inferir la comisión de una conducta punible. 
Esto significa que la Fiscalía está habilitada para renunciar a la persecución penal en el hurto, cuando cuenta con medios de convicción de los cuales pueda inferir la tipicidad de la conducta. Si, por ejemplo, advierte una causal de atipicidad objetiva, lo procedente no es la figura de la oportunidad, sino el archivo de la indagación o la preclusión de la investigación; la primera, a la luz del artículo 79 de la Ley 906 de 2004 y la sentencia C-1154 de 2005; la segunda, según el artículo 332 del mismo estatuto.

El archivo y la preclusión deben verse como mecanismos de política criminal, porque permiten anticipar la solución del conflicto. Sin embargo, la administración de justicia, con contadas excepciones, acude a estas figuras, siendo de mayor usanza el instituto de la oportunidad que, se reitera, sólo tendría cabida cuando existen los presupuestos probatorios, para entender que se ha cometido una conducta punible y que el investigado es su autor o partícipe.

Lo mismo sucede con las negociaciones y los preacuerdos, que la Ley 906 de 2004, a partir del artículo 348 , erigió como un mecanismo de terminación anticipada del proceso, fundados en postulados de justicia premial y consensual; se concede una rebaja de pena a cambio de la declaración de culpabilidad. En estos escenarios, la acción penal sí se activa; empero, se anticipa la pena y se evita el juicio.

El requisito sustancial de las negociaciones y los preacuerdos está dado por la existencia de un mínimo probatorio, del cual se pueda inferir la existencia del hecho y la culpabilidad (Garzón; Londoño; Martínez, 2007), pues de no de llegar a establecerse este mínimum, lo propio es el archivo o la preclusión de la investigación.

En lo que atañe a la política criminal, es ineludible un entendimiento adecuado del instituto de las negociaciones y los preacuerdos. Si bien pueden conllevar a una descongestión judicial y a la solución negociada del conflicto, en todo caso, propician una saturación del sistema penitenciario.

La Corte Constitucional ha dado lineamientos para evitar el hacinamiento carcelario. En la sentencia T-388 de 2013 expone como causas de dicho flagelo la aplicación de medidas de endurecimiento punitivo por parte de los operadores del sistema judicial. Se considera que la aplicación de las negociaciones y los preacuerdos sin un mínimo probatorio es una medida de endurecimiento punitivo que vulnera el Estado Social de Derecho y los núcleos constitucionales de política criminal, pues desconoce la última ratio del derecho penal, erigido para la exclusiva protección de bienes jurídicos, destinado a castigar las conductas que los lesionan gravemente y cometidos con culpabilidad.

\section{Factores que inciden en el hurto}

\section{Factores sociodemográficos}

Entre los factores sociodemográficos que inciden en el hurto se encuentran el consumo de drogas y el bajo grado de escolaridad. Asimismo, la variable de densidad poblacional afecta significativamente la probabilidad de la ocurrencia del delito (Cadena \& Letelier, 2018).

\section{Factores geoespaciales}

Existen lugares que facilitan el delito al disminuir los factores disuasivos vinculados a la eficacia policial; sectores que presentan una economía fuerte y una población flotante alta, así como lotes baldíos, zonas oscuras o sitios concurridos que favorecen la ocurrencia de la conducta (Ministerio de Defensa Nacional, 2016). 
Muchos hurtos ocurren en los vehículos de transporte público y en lugares con concentraciones masivas de personas como conciertos y otros espectáculos; asimismo, escenarios con baja infraestructura urbana como pavimento y luminarias, mientras que la existencia de áreas verdes disminuye la probabilidad (Cadena \& Letelier, 2018).

\section{Factores disuasivos vinculados a la eficacia policial}

La posibilidad de ocurrencia del hurto tiene dos determinantes básicos: la probabilidad de ser aprehendido y el tipo de castigo asociado a la falta. Estos aspectos son considerados por el delincuente potencial al momento de evaluar la decisión de llevar a cabo la conducta criminal. Si alguno de estos factores, o ambos presentan debilidades, o el individuo en sus cálculos previos considera que el riesgo es aceptable en relación con el beneficio que obtendría, esto promoverá la comisión de delitos (Cadena \& Letelier, 2018).

La posibilidad de ser aprehendido está también relacionada con el número de oficiales de policía por número de habitantes y el equipamiento como patrullas, motocicletas, y cámaras de vigilancia. Así, por ejemplo, la disponibilidad de patrullas con combustible y mantenimiento mecánico representa la posibilidad física de hacer patrullaje y movilizarse por el casco urbano y rural; contar con un número significativo de cámaras vigilancia distribuidas por la ciudad facilita la identificación y aprehensión de los delincuentes.

Otro elemento disuasivo está relacionado con la facilidad o dificultad que tenga el delincuente para monetizar los elementos robados. La comercialización es un componente esencial para el sostenimiento de este delito. Cuando el producto del hurto ingresa a la economía legal, por ejemplo, si es distribuido en casas de empeño o en tiendas de productos usados se incentiva la reproducción del ciclo delictivo. Tratándose del hurto, se identifican dos actores relevantes sin los cuales el mismo no tendría éxito ni sería atractivo: los comercializadores de objetos robados y el ciudadano que los compra (Ministerio de Defensa Nacional, 2016). Una política criminal frente al hurto debe entonces perseguir no solo al perpetrador del hurto, sino también a los comercializadores de elementos robados y crear campañas de sensibilización dirigida a la ciudadanía para que no compren productos de dudosa procedencia.

\section{Factores estructurales: desigualdad, pobreza y conflicto armado}

La desigualdad social en latinoamericana y su consecuente falta de opciones educativas y laborales en escenarios de inseguridad para amplios sectores de la población, son factores que contribuyen a que sus miembros sean susceptibles a unirse a grupos delincuenciales o a cometer delitos de manera individual (García, 2018).

Un resultado de dicha desigualdad social son los asentamientos ilegales en las periferias de las grandes ciudades, los cuales suelen tener diferentes problemáticas como insuficiencia de transporte, deficiencia en la prestación de servicios públicos, peligros de inundación por cercanía a cuerpos de agua o deslizamientos por tratarse de terrenos inestables, siendo no aptas para el desarrollo urbano. Estas zonas son habitadas generalmente por personas desplazadas o inmigrantes, de muy bajos recursos económicos y niveles educativos.

Este estado de vulnerabilidad es relevante para la política criminal porque constituye un factor de riesgo criminal. Una política pública que brinde oportunidades para mejorar la problemática socioeconómica que enfrentan estas personas repercutirá además en la reducción de los niveles de hurto. 


\section{Instrumentos de política pública criminal}

En la actualidad existen dos grandes instrumentos nacionales de política pública en materia de seguridad y convivencia ciudadana: el Plan Nacional de Desarrollo 2018-2022 'Pacto por Colombia, pacto por la equidad' y la Política Macro de Convivencia y Seguridad Ciudadana. Estos dos instrumentos establecen lineamientos que deben ser incorporados en los planes de desarrollo de los entes territoriales y los Planes Integrales de Seguridad y Convivencia Ciudadana.

\section{Plan nacional de desarrollo 2018-2020}

Para combatir el hurto en Colombia, el actual plan de desarrollo plantea la adopción de una estrategia que vaya más allá del control territorial soportado en el despliegue de las fuerzas militares y de policía, a un abordaje integral que incluya a las entidades públicas, privadas y organizaciones de la sociedad civil en la reducción de riesgos relacionados con el delito en especial la delincuencia juvenil.

Es necesario adoptar una visión multidimensional de la seguridad que implique la comprensión de las amenazas al Estado y a la población como fenómenos articulados que tienen incidencia en los campos económico, político, social y medioambiental y, por tanto, es necesario generar respuestas articuladas de Estado para enfrentarlas. (Plan Nacional de Desarrollo 2018-2022, p. 8)

Estas estrategias deben ir acompañadas de programas para la prevención temprana del delito en establecimientos educativos; evitar la desescolarización; cambiar prácticas culturales que valoren positivamente fenómenos criminales; facilitar la inserción social y económica de quienes han estado vinculados a grupos juveniles violentos; prevenir el consumo de sustancias psicoactivas y del alcohol; promover la recuperación de áreas deprimidas de algunos barrios y el casco urbano, espacios públicos y programas de renovación urbana; y promover planes en el desmantelamiento del micro-tráfico (Plan Nacional de Desarrollo 2018-2022)

\section{Política marco de convivencia y seguridad ciudadana}

Son múltiples las estrategias comprendidas en la política marco de convivencia y seguridad ciudadana contra el hurto (Presidencia de la República de Colombia, 2019). Estas deberán atender a sus distintas modalidades, alcances y agentes involucrados. Por ejemplo, el hurto de celulares suele estar asociado a organizaciones de delito transnacional, mientras que otras modalidades como "el cosquilleo" generalmente no están vinculados a redes de economías ilegales.

Las estrategias que se adopten frente al hurto deben ir más allá de quien comete la falta, y perseguir la red de valor del negocio ilícito y las bandas que lo llevan a cabo, particularmente en los casos de hurto a vehículos, motocicletas, bicicletas, residencias y comercio. Un aspecto clave frente a este delito es la judicialización efectiva; para ello se plantea la realización de análisis de contexto, investigaciones express, acciones contra delincuentes recurrentes y grupos de delincuencia organizada.

En la política marco se prioriza la persecución del delito de receptación como una forma de atacar la red de valor del hurto. Al sancionar la receptación se golpea directamente el hurto, toda vez que al reducir el mercado de los bienes obtenidos robados se disminuye el valor de estos. Frente al hurto de celulares, se pretende perseguir tanto a quien hurte el celular como a aquel que compre celulares hurtados. Igualmente, 
se propone desarrollar campañas para que uno y otro reciban el mismo reproche social y judicialmente se concentren los esfuerzos para sancionar a los dos.

La estrategia de georeferenciación del delito consiste en que los esfuerzos contra el hurto a personas se concentran en las zonas con mayor número de casos para intervenir los ambientes que los propician. Para ello, se busca emplear dispositivos de vigilancia atendiendo a los horarios en que estos se producen.

La organización ciudadana juega un papel muy importante en la lucha contra el hurto. El marco prevé la promoción de la Red de Participación Cívica que articule los gremios de la economía y las juntas de acción comunal con las autoridades para realizar actividades de vigilancia de las calles, vecindarios y espacios donde cumplen su actividad económica. Esto en el marco que establece la jurisprudencia constitucional respecto al deber de solidaridad y los límites de la participación ciudadana en seguridad. La información ciudadana destinada a prevenir dicho delito y a sancionar a los infractores es un factor disuasivo para su realización.

Otra de las medidas contempladas en este instrumento de política criminal es la disuasión. Se exhorta a los dirigentes locales a diseñar acciones tendientes a que el delincuente encuentre que el costo de cometer el hurto es mayor al beneficio que puede obtener, al igual que frente al delito de receptación. Tres cosas son determinantes para eso: la presencia notoria de la policía de vigilancia en las zonas más afectadas por esta modalidad criminal; el uso de cámaras de video y la respuesta inmediata y visible de la policía ante un caso.

\section{Conclusiones}

Las respuestas que se den a la problemática del hurto deben integrar diversos elementos: uno político (el planteamiento de políticas públicas en materia de seguridad), uno económico (la destinación de los recursos necesarios para la implementación de dichas políticas orientadas a atacar las principales causas de este delito) y uno cultural (socialización de las políticas públicas a los habitantes y el fomento de denuncias).

La política criminal debe tener un enfoque integral en el cual, las penas no sean la única opción. La privación de la libertad debe ser una medida excepcional, de última ratio. El derecho penal y procesal penal deben lograr confluencias de entendimiento y propiciar mecanismos de terminación anticipada del conflicto, de manera que estén en la capacidad de reivindicar el principio de culpabilidad, el de lesividad y el de exclusiva protección de bienes jurídicos, como principios constitucionales de política criminal que deben conjugarse con las razones de pragmatismo, para hacer del sistema punitivo un escenario eficiente de restauración y retribución, que contribuya a superar la crisis del hacinamiento carcelario.

Se deben adoptar programas de resocialización y sanciones alternativas que permitan a los infractores encontrar un espacio en la sociedad que le brinde las garantías para no caer nuevamente en la delincuencia. La política criminal debe ir acompañada de la política social. Medidas que hagan frente a las problemáticas que afectan a las comunidades vulnerables, como aquellas tendientes a reducir el desempleo y a elevar los niveles educativos, repercutirán en la disminución del riesgo de caer en la delincuencia o en las drogas.

La política pública de la lucha contra la criminalidad en el país en los últimos años ha estado orientada a la creación de espacios que promuevan conciencia ciudadana en lo referente al deber de respetar la ley y la convivencia pacífica; al desarrollo de medidas de prevención del delito y el establecimiento de canales de interacción entre la policía y la comunidad. El enfoque de los derechos humanos debe guiar la propuesta, implementación y evaluación de cualquier política pública de la lucha contra la criminalidad. 


\section{Referencias Bibliográficas}

Acuña, J. \& Muñoz, J. (2006). Principio de oportunidad y Preacuerdos, pp. 116-136. En: Autores Varios. Sistema Penal Acusatorio. Rol del perito y de la policía judicial. Bogotá: Universidad Nacional de Colombia.

Agudelo, N. (2008). Grandes corrientes del derecho penal. Escuela positivista: introducción a la lectura de César Lombroso, Rafael Garofalo y Enrico Ferri. Bogotá: Editorial Temis.

Alexy, R. (1989). Justicia como corrección. Alicante: Doxa.

Aparicio, J. (22 de febrero de 2009). Foro de Seguridad. Recuperado el 23 de marzo de 2019, de Foro de Profesionales Latinoamericanos de Seguridad: http://www.forodeseguridad.com/artic/discipl/4108. htm

Aponte, A. (2010). Principio de oportunidad y política criminal. De la discrecionalidad técnica a la discrecionalidad política reglada. Bogotá: Consejo Superior de la Judicatura, Sala Administrativa, Escuela Judicial Rodrigo Lara Bonilla.

Asamblea Nacional Constituyente. (4 de julio de 1991). Constitución Política de Colombia. Bogotá, Colombia: gaceta constitucional 114.

Baratta, A. (2004). Criminología crítica y crítica del derecho penal. Introducción a la sociología jurídico penal. Buenos Aires: Siglo XXI Editores.

Benavides, F. (2016). Política criminal y seguridad, pp. 123-148. En: Benavides, F; Binder, A; Villadiego, C; Niño, C. La reforma a la justicia en América Latina. Bogotá: Friedrich-Ebert-Stiftung en Colombia (Fescol).

Botero \& Uribe (2017). Preacuerdos y Negociaciones entre la Fiscalía y el imputado o acusado. Bogotá: Leyer Editores.

Cadena, P. \& Letelier, L. (2018). “Determinantes de los Delitos de Mayor Connotación Social en la Región Metropolitana. Análisis en base a un modelo de regresión logística". Política criminal, 13(26), Art. 14, 1170-1189.

Carnevali, R. (2008). Derecho penal como última ratio. Hacia una política criminal racional. Revista lus et Praxis - año $14-n^{\circ} 1: 13-48$.

Carrara, F. (2000). Programa del Curso de Derecho Criminal. Traducción realizada por Octavio Béeche y Alberto Gallegos. Tomo II. San José de Costa Rica: Editorial Jurídica Continental.

Congreso de la República de Colombia. (1 de septiembre de 2004). Por la cual se expide el Código de Procedimiento Penal. [Ley 906 de 2004]. Bogotá: DO: 45.658.

Congreso de la República de Colombia. (20 de agosto de 1993). Por la cual se expide el Código Penitenciario y Carcelario. [Ley 65 de 1993]. DO: 40.999.

Congreso de la República de Colombia. (20 de septiembre de 2012). Por medio de la cual se establecen estímulos tributarios y otros, con el fin de adoptar medidas especiales para la rehabilitación e inclusión social de jóvenes con alto grado de emergencia social, pandillismo y violencia juvenil. [Ley 1577 de 2012]. DO: 48.559.

Congreso de la República de Colombia. (24 de julio del 2000). Por la cual se expide el Código Penal [Ley 599 de 2000]. DO: 44.097.

Congreso de la República de Colombia. (24 de julio del 2000). Por la cual se expide el Código de Procedimiento Penal. [Ley 600 de 2000]. DO: 44.097.

Congreso de la República de Colombia. (25 de julio de 2005). Por la cual se dictan disposiciones para la reincorporación de miembros de grupos armados organizados al margen de la ley, que contribuyan de manera efectiva a la consecución de la paz nacional y se dictan otras disposiciones para acuerdos humanitarios. [Ley 975 de 2005]. DO: 45.980. 
Congreso de la República de Colombia. (28 de julio de 2007). por medio de la cual se reforman parcialmente las Leyes 906 de 2004, 599 de 2000 y 600 de 2000 y se adoptan medidas para la prevención y represión de la actividad delictiva de especial impacto para la convivencia y seguridad ciudadana. [Ley 1142 de 2007]. DO: 46.673.

Congreso de la República de Colombia. (29 de julio de 2016). Por la cual se expide el Código Nacional de Policía y Convivencia. [Ley 1801 de 2016]. DO: 49.949.

Congreso de la República de Colombia. (31 de julio de 2007). Por medio de la cual se establece el tratamiento de las pequeñas causas en materia penal. [Ley 1153 de 2007]. DO: 46.706.

Congreso de la República de Colombia. (8 de noviembre de 2006). Por la cual se expide el Código de la Infancia y la Adolescencia. [Ley 1098 de 2006]. Bogotá: DO: 46.446.

Congreso de la República de Colombia. (de 24 de enero de 2001). Por la cual se modifican normas relativas a la conciliación y se dictan otras disposiciones. [Ley 640 de 2001]. DO: 44.303.

Congreso de la República de Colombia. (de 6 de julio de 2015). Por medio de la cual se modifica parcialmente la ley 906 de 2004 en relación con las medidas de aseguramiento privativas de la libertad. [Ley 1760 de 2015]. DO: 49.565.

Corte Constitucional. (13 de junio de 2013) Sentencia T-338. [M.P. Alberto Rojas Ríos]

Corte Constitucional. (16 de diciembre de 2015) Sentencia T-762. [M.P. Gloria Stella Ortiz Delgado]

Corte Constitucional. (20 de junio de 2001) Sentencia C-646. [M.P. Manuel Jose Cepeda Espinosa]

Corte Constitucional. (22 de junio de 2016) Sentencia C-326. [M.P. Gabriel Eduardo Mendoza Martelo]

Cote, G. (2007). La necesidad de la pena. Reflexiones a partir de los artículos 3 y 4 del Código Penal Colombiano. Vniversitas, No. 114, pp. 191-226.

Cruz, F. (2011). La violencia del Derecho Penal. Represión punitiva, discriminación y la postergación del Estado social. Revista Digital de Maestría en Ciencias Penales de la Universidad de Costa Rica (3), 688-719.

Duce, M.; Riego, C. (2007). Proceso Penal, Santiago: Editorial Jurídica.

Echevarría, R. (2008). Derecho penal material y principio de oportunidad, pp. 229-272. En: Posada, R. (Coord.) Temas de Derecho Penal. Bogotá: Editorial Temis- Universidad de los Andes.

Faroppa, J. (2005). Políticas públicas integrales: Elementos constitutivos. En I.-A. D. Bank (Ed.), Políticas públicas integrales: Elementos constitutivos. Medellin: Inter-American Development Bank. https:// publications.iadb.org/es/publicacion/16012/politicas-publicas-integrales-elementos-constitutivos (Recuperado 30 de junio de 2020).

Fiscalía General de la Nación (2019). Rendición de cuentas 2018-2019. Bogotá D.C.: Fiscalía General de la Nación.

García, R. (Noviembre de 2018). ¿La desigualdad genera delincuentes? Forbes México. Obtenido de https:// www.forbes.com.mx/la-desigualdad-genera-delincuentes/

Garzón, A; Londoño, C. (2006). Principio de oportunidad. Bogotá: Editorial Nueva Jurídica.

Garzón, A; Londoño, C; Martínez, G. (2007). Negociaciones y preacuerdos. Tomo I. Bogotá: Editorial Nueva Jurídica.

Garzón, A; Londoño, C; Martínez, G. (2007). Negociaciones y preacuerdos. Tomo II. Bogotá: Editorial Nueva Jurídica

Gimeno, J.; Moreno V.; Cortés V. (2001). Lecciones de Derecho procesal penal. Madrid: Constitución y leyes, Colex. 
Gómez, C. (2007). La oportunidad como principio complementario del proceso penal. 2aa Edición. Bogotá: Ediciones Nueva Jurídica.

Guerrero, O. (2017). Fundamentos teórico constitucionales del nuevo proceso penal. 2á Edición. Bogotá: Ediciones Nueva Jurídica. Guerrero, L. (2007). Seguridad pública y prevención del delito en el Estado social de derecho. Dikaion, 21(16), 251-272.

Gutiérrez, M. (2015). Política Criminal y Prevención. Bogotá: Universidad Externado de Colombia.

Jescheck, H. (1993). Tratado de Derecho Penal, Parte General. Cuarta Edición, corregida y ampliada. Traducción de José Luís Manzanares Samaniego. Granada: Comares.

Juárez, A., \& Medina, M. (2011). Política criminal (México-Chile). Revista Mexicana de Justicia (18), 163-214. doi:http://dx.doi.org/10.22201/iij.24487929e.2011.18

Ministerio de Defensa Nacional (2016). Estudio Criminológico. Hurto a personas y su afectación en la economía y contexto social. Bogotá D.C.: Policía Nacional de Colombia.

Ministerio de Justicia (28 de marzo de 2019). Sistema de estadísticas en justicia. Obtenido de Gobierno de Colombia, MinJusticia: http://sej.minjusticia.gov.co/PoliticaCriminal/Paginas/Contexto.aspx

Nino, C. (s.f.). El castigo como respuesta a las violaciones a los derechos humanos. Una perspectiva global. Artículo traducido al castellano por el Centro de Derechos Humanos, Facultad de Derecho, Universidad de Chile, y reproducido con la autorización expresa de Emecé Editores S.A., Argentina. Recuperado de: [https://biblioteca.iidh-jurisprudencia.ac.cr/index.php/documentos-en-espanol/ verdad-justicia-y-reparacion/1320-el-castigo-como-respuesta-a-las-violaciones-a-los-derechoshumanos-una-perspectiva-global/file]

Núñez, L. (2009). Un análisis abstracto del Derecho Penal del Enemigo a partir del Constitucionalismo Garantista y Dignatario. Santiago: Universidad Católica de Chile.

Páez, A., \& Torres, P. (2016). Elementos para una política de seguridad urbana. Madrid: Universidad Complutense de Madrid.

Pavarini, M. (2002). Control y dominación. Teorías criminológicas burguesas y proyecto hegemónico. (T. a. Muñagorri, Trad.) Buenos Aires, Argentina: Siglo XXI Editores.

Policía Nacional. (2018-2019). Estadística Delictiva. Policía Nacional. Obtenido de https://www.policia.gov. co/grupo-informaci\%C3\%B3n-criminalidad/estadistica-delictiva

Presidencia de la República de Colombia (2019). Política marco de convivencia y seguridad ciudadana. Bogotá D.C.: Ministerio de Defensa Nacional.

Presidencia de la República de Colombia. (16 de octubre de 2014). Por el cual se reglamenta el Consejo Superior de Política Criminal, su funcionamiento y todos los asuntos relacionados con las demás instancias técnicas que se requieran para su adecuado desarrollo. [Decreto 2055 de 2014] D0: 49306

Presidencia de la República de Colombia. (2017). Politica Criminal del Estado Colombiano. Bogotá: Presidencia de la República. Obtenido de http://www.politicacriminal.gov.co/Portals/0/documento/politica\%20 criminal\%20(1).pdf?ver=2017-03-09-180338-790

Presidencia de la República de Colombia. (2018). Plan Nacional de Desarrollo 2018-2022. Pacto por Colombia, pacto por la equidad. Bogotá: Departamento Nacional de Planeación.

Presidencia de la República de Colombia. (21 de septiembre de 2015). por el cual se crea el Sistema Nacional de Coordinación de Responsabilidad Penal para Adolescentes (Sncrpa) y se dictan otras disposiciones. [Decreto 1885 de 2015] DO: 49.642

Reyes, J. (1996). Política Criminal, Reacción Social Punitiva. Guatemala: Universidad Rafael Landivar. 
Reyes, L. (2010). Allanamiento a cargos y preacuerdos en el sistema penal acusatorio. Bogotá, D.C.: Editorial Leyer.

Rodríguez, C. (2017). Análisis de la implementación de la política pública de seguridad ciudadana en Bogotá (1995-2015). Madrid: Universidad Complutense de Madrid.

Roth, A.N. (2002). Políticas Publicas: Formulación, Implementación y Evaluación. Bogotá: Ediciones Aurora.

Roxin, C. (1981). Culpabilidad y prevención en Derecho Penal. Madrid: Editorial Reus.

Soto, M. (2010). Las políticas públicas en la prevención del delito en Guatemala. (Trabajo de grado) Universidad De San Carlos De Guatemala, Facultad De Ciencias Jurídicas y Sociales, Guatemala.

Tamayo, F. (2016). La limitada capacidad del concepto de populismo punitivo como herramienta de interpretación del sistema penal colombiano. Revista Criminalidad, 58 (3): 21-35.

Urbano, J. (2018). La nueva estructura probatoria del proceso penal. Bogotá: Editorial Nueva Jurídica.

Velásquez, F. (2007). Manual de Derecho Penal Parte General. Medellín: Comlibros. 
